\title{
A INCLUSÃO E SUA IMPORTÂNCIA NA EDUCAÇÃO ESPECIAL
}

\author{
Ellen Simone Alves De Souza ${ }^{1}$ \\ Geicele Gomes Barbosa ${ }^{2}$ \\ Mayara Priscila Brauna Miatelo ${ }^{3}$ \\ Michelli Carla De Souza ${ }^{4}$
}

RESUMO: No presente estudo discute a importância da sala de recursos como parte do processo de inclusão, no contexto escolar, enfocando seus objetivos e sua organização, considerando principalmente, as diretrizes para a educação especial e recomendações de organizações nacionais e internacionais para essa modalidade educacional. No entanto, um dos empecilhos na educação dos alunos portadores de deficiência é a necessidade de uma metodologia específica, bem como de recursos. A questão da inclusão, dessas crianças, insere-se no contexto das discussões a questão das adequações necessárias da escola, para a integração das pessoas portadoras de deficiências enquanto cidadãos, com direitos e deveres de participação e contribuição social. Com este estudo busca-se analisar a reformulação de políticas educacionais e de implementação de projetos educacionais voltados para a inclusiva e nesta a sala de recursos que se planejada adequadamente poderá contribuir para a aprendizagem e desenvolvimento dos alunos evitando a reprovação e a evasão escolar.

Palavras-chaves: Importância. Inclusão. Educação especial.

ABSTRACT: This study discusses the importance of the resource room as part of the inclusion process in the school context, focusing on its objectives and organization, considering mainly the guidelines for special education and recommendations from national and international organizations for this educational modality. However, one of the obstacles in the education of students with disabilities is the need for a specific methodology, as well as resources. The issue of the inclusion of these children is included in the context of the discussions, the issue of the necessary adaptations of the school, for the integration of people with disabilities as citizens, with rights and duties of participation and social

\footnotetext{
I Licenciatura em pedagogia, com especialização em anos iniciais e educação infantil. E-mail: mmichellicarlai3@hotmail.com.

2 Licenciatura em pedagogia, com especialização em educação infantil. E-mail: ellendirceu@outlook.com.

${ }^{3}$ Licenciatura em pedagogia, com especialização em educação infantil com ênfase na inclusão. E-mail: mpbrauna@gmail.com.

4 Licenciatura em pedagogia, com especialização em psicopedagogia, bacharelada m serviço social. Email: geicelegobarbosa@gmail.com.
} 
contribution. This study seeks to analyze the reformulation of educational policies and the implementation of educational projects aimed at including, and in this, the resource room that if properly planned can contribute to the learning and development of students, avoiding school failure and dropout.

Keywords: Importance. Inclusion. Special education.

\section{INTRODUÇÃO}

Atualmente, muito se tem falado em inclusão, este conceito aparece na medida em que seu contraponto - a exclusão - se agiganta de todas as formas em nossa sociedade. Um dos segmentos que mais evidencia esse processo excludente é o das crianças com necessidades educativas especiais.

Percebe-se grande inquietação e preocupação por parte de profissionais da educação em relação à inclusão. Quando se consideram as recentes diretrizes, as recomendações nacionais e internacionais sobre o assunto, percebem-se a necessidade de uma reflexão sobre a inclusão, traduzida para o contexto educacional brasileiro.

A educação, como um processo com constantes transformações deve ser acompanhada por todos os profissionais da área, seja do setor administrativo, coorporativo, tecnológico, pedagógico e até psicológico. Hoje, professores, alunos, pais e comunidade em geral têm necessidades diferenciadas de um tempo atrás.

A escola, enquanto responsável na formação do indivíduo, precisa acompanhar as mudanças da sociedade. A questão da inclusão de crianças com necessidades educativas especiais na rede regular de ensino insere-se no contexto das discussões, cada mais em evidência, relativas à integração de pessoas portadoras de deficiências enquanto cidadãos, com seus respectivos direitos e deveres de participação e contribuição social.

Uma das grandes dificuldades é encontrar professores qualificados ou treinados para bom desempenho frente à realidade encontrada. Necessita-se de elementos humanos que além de seus conhecimentos tenham dedicação e amor para desempenhar esta missão, capazes de suprir as carências afetivas e emocionais dos alunos, resgatando sua autoestima e tornando-o membro participativo na sociedade. 
Esta interface, da educação regular com a educação especial, deve acontecer na escola regular, mas com sala de recursos e pessoal técnico para desenvolver ali, atividades que possam complementar o aprendizado de sala de aula. É com esta sala de recursos que se pode evitar que o aluno seja desestimulado e acabe por evadir-se da escola.

\section{A INCLUSÃO E A EDUCAÇÃO ESPECIAL}

Para iniciar a abordagem da temática Inclusão versus educação especial, é fundamental destacar alguns aspectos da História da Educação Especial, uma vez que são a partir dela que os preceitos filosóficos, que hoje dão base ao processo inclusivo, foram se constituindo.

As sociedades, em cada momento histórico, deram ao deficiente a concepção e o destino que mais lhes convinham. Torna-se assim importante a realização de uma retrospectiva histórica desde a antiguidade para compreender como a deficiência era vista e refletir sobre os aspectos positivos que aconteceram com as mudanças ocorridas no final do século XX.

Outras tribos consideravam os deficientes como morada dos maus espíritos, tornando possível a normalidade dos demais membros do seu grupo de convívio.

De acordo com Silva, na Antiguidade os deficientes eram vistos como negligentes, sendo ignorados, abandonados e excluídos da sociedade. É possível afirmar que, com o advento do Cristianismo, as pessoas deficientes passaram a ser vistas como portadoras de anormalidades de origem sobrenatural. Isso porque, como desenvolvimento da ciência, a própria religiosidade passou por transformações.

Nesse contexto, os homens começaram a se preocupar em explicar como os processos de desenvolvimento humano poderiam assumir caminhos diferentes, por ausência ou deformação de órgãos e estruturas orgânicas, ou pelo não funcionamento adequado dos mesmos. Tal como foi posta a preocupação em classificar os eventos da 
natureza, para se tentar dominá-la, também passaram a preocupar-se em descrever e classificar as deficiências físicas do ser humano.

Entretanto, somente após o século XVIII os portadores de deficiência começam a serem vistos como pessoas que poderiam conviver socialmente e, no século XIX, época de grandes descobertas científicas, passou-se aos estudos dos deficientes na busca do tratamento para seus problemas.

Ao se prosseguir com o fio da História, de acordo com Jiménez, os deficientes mentais, nos séculos XVII a XVII eram internados para tratamento clínico em manicômios, orfanatos, prisões e outros tipos de instituições, locais estes totalmente inapropriados, pois não só fugiam à proposta imposta de tratamento, como eram segregados juntamente com os velhos, pobres, delinquentes e até assassinos.

Como nesta época não havia desenvolvimento da ciência que pudesse esclarecer sobre os fatores que revelam os indivíduos a apresentarem deficiências, ainda prevaleciam explicações religiosas e místicas.

A elas correspondiam práticas sociais como a de não expor em público os seus portadores. Dentre eles, o da Deficiência Mental e Severa, conhecidas à época por outras nomenclaturas, condicionadas às especificidades históricas de cada época.

Ainda conforme comenta Jiménez, no final do século XVIII e início do século XIX, inicia-se o período da institucionalização, surgindo assim os primeiros Institutos e Hospitais que tratavam à deficiência como uma doença. Havia uma preocupação generalizada em atenderem a deficiência sob uma visão médica.

A história da educação pública mistura-se à própria história do atendimento às diversidades, pois, em meio ao movimento de escola para todos, surgiram as escolas públicas para os filhos de operários, a proibição às crianças de trabalharem em fábricas, tendo assim que irem para a escola.

Nesta época de luta pelo acesso de todos à educação, a sociedade começou a se preocupar com as crianças que não acompanhavam os conteúdos. Desse modo, o estudo das deficiências e das possibilidades de se criar métodos educativos para 
educar as crianças portadoras de necessidades especiais nas áreas de deficiência mental, visual, auditiva e física ganhou destaque.

Com esse movimento, foi constituído, assim, um subsistema de Educação Especial diferenciado, mesmo estando dentro do sistema educativo geral. Nos meados do século XX, a discussão acerca da integração das crianças deficientes no Ensino Regular foi ganhando força, na mesma proporção em que alguns princípios democráticos passaram a ser mais debatidos, tais como a integração, a normalização, a individualização, a legitimidade, a efetividade dos modelos de atendimento educacional.

Foi no Canadá, em 1972, que se publicou o primeiro livro a respeito deste princípio, como nos mostra Jiménez. Segundo as Diretrizes e os Pressupostos Teórico-Metodológicas para a Educação Especial, no Brasil, bem como em partes de outros países, a preocupação com a deficiência é remota, embora ela não fosse generalizada. Em São Paulo, por exemplo, no período Colonial já havia uma instituição particular na área de deficiência física, junto com a Irmandade da Santa Casa de Misericórdia.

Em 1854, foi criado o primeiro Instituto de Cegos no Rio de Janeiro, atualmente Instituto Benjamim Constant e, em I856, o Instituto de SurdosMudos, hoje Instituto Nacional de Educação de Surdos - INES, conforme citado nas Diretrizes Teórico-Metodológicas para a Educação Especial. Foi na década de 30 que teve origem a preocupação em oferecer aos portadores de necessidades especiais uma educação escolar.

Com o início do movimento escola novista, a educação passou a utilizar métodos mais ativos, dando ênfase a atividades em grupo, práticas de trabalhos manuais, valorizando-se o estudo da psicologia experimental e a criança passaram a ser o centro do processo educacional. Pode-se destacar ainda que Helena Antipoff, psicóloga e educadora, em 1932, por sua iniciativa própria fundou a Sociedade Pestalozzi de Belo Horizonte, tendo assim início a primeira experiência educacional institucionalizada para portadores de deficiência. 
Nesse mesmo espírito, foi fundada a Fazenda Rosário em Belo Horizonte, em 1940, para a educação dos excepcionais e foram criados também os serviços de diagnósticos, classes especiais e foi iniciada a organização da Associação dos Pais e Amigos dos Excepcionais - APAES. É importante salientar que se intensificou o processo de criação de novas instituições a partir da década de 8o, principalmente na área da Deficiência Mental.

Nos relatos ativos, demostra o movimento apeanho, e também a incidência de um número maior de casos de deficiência mental entre a população das escolas especiais na área mental, fez com que ocorresse uma expansão gradativa da Educação Especial em alguns momentos. Em 196I, por exemplo, com a lei 4024/6I foram estabelecidas as Diretrizes e Bases para a Educação Nacional.

Logo nesta fase tinha-se uma visão tradicionalista, ou seja, embora não fossem mais tomados como demoníacos ou como dignos de serem escondidos, de um modo geral, ainda eram considerados incapazes e improdutivos e como tal deveriam ficar à margem do progresso educacional.

Onde a Educação Especial, em 1996, foi destacada com mais ênfase, sendo contemplada dentro da LDB - Lei de Diretrizes e Bases da Educação Nacional - Lei 9394/96, Capítulo V, assinalando assim a política norteadora para a Educação Especial. Os demais artigos deste capítulo da lei também falam da Educação Especial.

\section{A IMPORTÂNCIA DA INCLUSÃO DA EDUCAÇÃO ESPECIAL NO AMBIENTE ESCOLA}

Com tudo, querendo agir no sentido de minorar a discriminação sofrida pelas pessoas portadoras de necessidades especiais.

Nos Princípios Básicos da educação Especial está expressa a preocupação com o desenvolvimento integral do educando e, acima de tudo, respeitando-o e proporcionando uma educação de qualidade visando torna-lo um indivíduo produtivo na sociedade em que vive.

Coloca a importância da educação se assentar em princípios democráticos alicerçados na dignidade, liberdade e igualdade. 
Individualização: devem-se valorizar as diferenças individuais, sejam as existentes entre os portadores de necessidade especiais e as pessoas ditas normais, seja comparando entre si os próprios portadores de necessidades especiais.

Logo, oferecer-lhes condições de agir e interagir com todos e proporcionarlhes um atendimento educacional adequado a cada indivíduo que apresenta necessidades especiais, respeitando seu ritmo, aprendizagem e diferenças.

O epistemológico da construção do real: refere-se à conciliação, ou seja, estar de acordo com o que é necessário fazer para atender às aspirações e interesses dos portadores de necessidades especiais, oferecendo atendimento a todas as necessidades do educando de Educação Especial e se utilizar todos os meios disponíveis e de toda ordem.

E assim efetividade dos modelos de atendimento educacional: alicerça-se na qualidade das ações educativas, envolvendo três elementos: infra-estrutura administrativa, recursos humanos e materiais, hierarquia de poder, consenso político.

\section{CONSIDERAÇÕES FINAIS}

Sabe-se que a referida Educação inclusiva, que propõe igualdade de oportunidades e a valorização das diferenças seja ela qual for como for. Seu principal objetivo é assegurar o acesso, a participação e a aprendizagem de todos os indivíduos, sem qualquer exceção.

Onde a Educação inclusiva é uma modalidade de ensino que permite a convivência e a integração das pessoas com deficiência dentro da escola regular garantindo a todos o direito à escolarização.

A premissa básica da educação inclusiva é o respeito à diversidade. Sabemos que todos as pessoas são diferentes, têm suas habilidades e suas dificuldades, e por isso devemos ter um olhar individualizado para cada uma, respeitando suas especificidades e assim se faz a educação inclusiva no ambiente escolar.

Visto que, ao ter me foco em garantir a inclusão de todos os estudantes é um dos grandes desafios atualmente enfrentados pelas escolas. 
Além das diferenças culturais e sociais entre os jovens, as instituições de ensino também devem estar preparadas para garantir todo o suporte necessário a crianças que apresentem qualquer tipo de necessidade especial, pois a escola é a segunda casa dos alunos, o mesmo tem que sentir em casa, ter alegria de estar no ambiente da escola, logo a vontade de aprender e conviver em sociedade.

\section{REFERÊNCIAS}

BIANCHETTI, Lucídio. Aspectos históricos da educação especial. Revista Brasileira de Educação Especial. $\quad$ v.2, n.3, $\quad$ I995, $\quad$ p.7-I9. BARROCO, Sônia. Repensando a interação do aluno portador de necessidades educativas especiais no ensino regular. Projeto de Ensino. Universidade Estadual de Maringá. 1998.

BRASIL. Saberes e práticas da inclusão : altas habilidades : superdotação - 2. ed. rev. - Brasília : MEC, 2003. Educação Especial no Brasil. Brasília: Secretaria de Educação Especial, 1994. Ministério da Educação e Cultura. Fundação Roquete Pinto. Um salto para ofuturo. Boletim 08/1995.

Ministério da Educação e cultura. Lei de Diretrizes e Bases da Educação (Lei 9394/96). Brasília: 1996.

Parâmetros Curriculares Nacionais: Adaptações Curriculares - estratégias para educação de alunos com necessidades educacionais especiais. Brasília: MEC/SEF/SEESP, 1999 .

CARVAlHO, M. A. Educação Especial - Tendências de Hoje. In: Projeto Crescer, Fundação Brasileira de Educação. Niterói: Centro Educacional de Niterói, 1995.

CENESP-Centro Nacional de Educação Especial. Educação Inclusiva. Rio de Janeiro, p. 26, 1994 .

Subsídios para organização e funcionamento de serviços de Educação Especial. Rio de Janeiro, 1984 . 
FONSECA, V. da. Uma introdução às dificuldades de aprendizagem. Lisboa: Ed. Notícias, 1987. MACHADO, kátia. Como a escola pode tornar-se inclusiva? Disponível no site: www.inclusao.com.br/index.

Acesso em 09.05.2021 MANTOAN, M.T.E. Educação de deficientes mentais: o itinerário de uma experiência. Dissertação de Mestrado. Campinas: UNICAMP/ Faculdade de Educação. 1987.

MARCOS J. da Silveira. Deficiência, educação escolar e necessidades especiais: reflexões sobre inclusão sócia educacional. São Paulo: Editora Mackenzie, 2002. Fundamentos de Educação Especial. Séries Cadernos de Educação. São Paulo: Biblioteca Pioneira de Ciências Sociais: 1982. MASINI, Elcie F. S. - Avaliação; Inclusão; Promoção automática; Exclusão. Apresentado no Fórum Pp - "Debate Nacional sobre Avaliação e Aprendizagem". São Paulo: ABPp, 2001. MRESH, Leni Magalhães. O que é educação inclusiva. São Paulo: Faculdade de Educação da USP, 2000. OLIVEIRA, M . A. Educação inclusiva: limites e possibilidades. São Paulo: Fiorin, 2004

REVISTA INTEGRAÇÃO, Ministério da Educação e do Desporto/Secretaria de Educação Especial. Ano 7 - № 16 - 1996, pp. 19-26.

SANTOS, M. Ribeiro. Inclusão. Revista Nova Escola, 2005.

WERNECK, Claudia. A educação inclusiva. In: MACHADO, kátia. Como a escola pode tornar-se inclusiva? Disponível no site: www.inclusao.com.br/index. Acesso em 20. 